This item was submitted to Loughborough's Research Repository by the author.

Items in Figshare are protected by copyright, with all rights reserved, unless otherwise indicated.

\title{
Tribology of the ring-bore conjunction subject to a mixed regime of
} lubrication

PLEASE CITE THE PUBLISHED VERSION

PUBLISHER

(C) IMechE / Professional Engineering Publishing

VERSION

VoR (Version of Record)

LICENCE

CC BY-NC-ND 4.0

\section{REPOSITORY RECORD}

Mishra, P.C., Homer Rahnejat, and P.D. King. 2019. "Tribology of the Ring-bore Conjunction Subject to a Mixed Regime of Lubrication”. figshare. https://hdl.handle.net/2134/4621. 
This item was submitted to Loughborough's Institutional Repository (https://dspace.lboro.ac.uk/) by the author and is made available under the following Creative Commons Licence conditions.

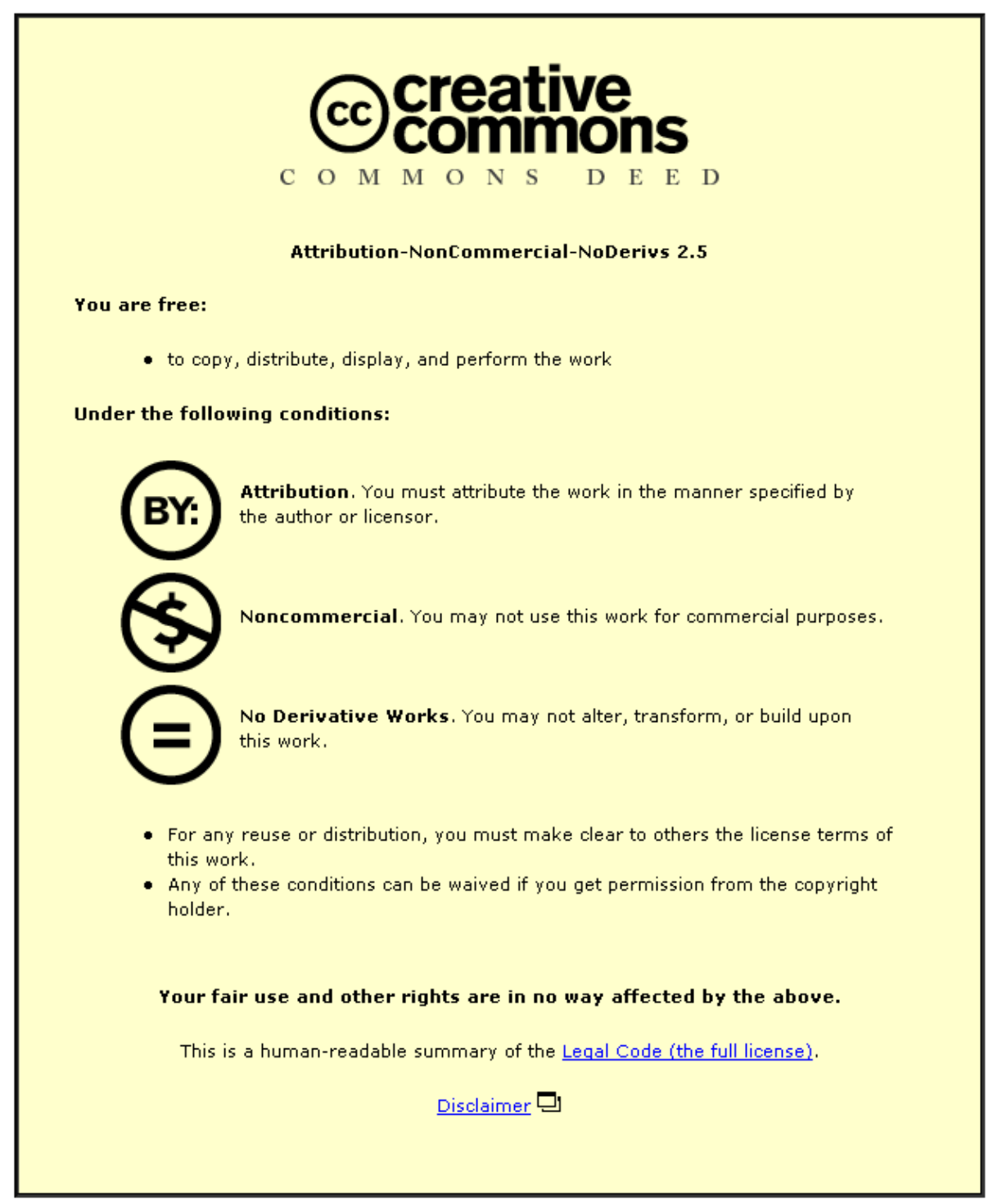

For the full text of this licence, please go to: http://creativecommons.org/licenses/by-nc-nd/2.5/ 


\title{
Tribology of the ring-bore conjunction subject to a mixed regime of lubrication
}

\author{
P C Mishra, H Rahnejat ${ }^{*}$, and P D King \\ Wolfson School of Mechanical and Manufacturing Engineering, University of Loughborough, Loughborough, UK
}

The manuscript was received on 11 June 2008 and was accepted after revision for publication on 27 August 2008.

DOI: 10.1243/09544062JMES1220

\begin{abstract}
This paper provides a detailed analysis of the compression ring-bore/liner conjunction. The analysis includes ring-bore conformability and global in-plane deformation of ring fitted in situ. The analysis for fitted ring in an out-of-round bore shows very good agreement with precise measurements, using a coordinate measuring machine. The analysis also includes the lubricated conjunction under a transient regime of lubrication, taking into account combined elastohydrodynamics and asperity interactions. The transient nature of the tribological conjunction has been demonstrated, particularly the prevalent mixed/boundary regime of lubrication at the top and bottom dead centres.

The analysis is applied to a high performance motorbike engine subjected to very high impact loads and engine speeds of the order of $13000 \mathrm{r} / \mathrm{min}$. Furthermore, the predictions of the model show good conformance to the measurements of friction reported by other research workers.
\end{abstract}

Keywords: piston compression ring, ring deformation, elastohydrodynamic lubrication, asperity contacts

\section{INTRODUCTION}

Parasitic losses in an internal combustion (IC) engine account for 15 to 20 per cent of the total losses. Piston skirt and ring-pack are the primary sources of friction in the engine (around 40 per cent) with losses due to ring-pack being the largest, such that the compression rings are responsible for 4 to 5 per cent of all losses in a typical multi-cylinder IC engine. Given that 4 per cent reduction in parasitic losses translates directly to 1 per cent gain in fuel efficiency, the lack of very detailed analysis, except for a few notable contributions [1-3], is rather surprising.

A detailed analysis should initially take into account the degree of conformability of the ring to the bore surface, as well as the out-of-roundness of the latter [4]. This translates to the determination of global deformation of an incomplete ring when fitted in situ due to the generated elastic force [5-7]. The end-gap of the fitted incomplete ring is further reduced with applied pressure and the total outward force on the

\footnotetext{
*Corresponding author: Wolfson School of Mechanical and Manufacturing Engineering, University of Loughborough, Loughborough, Leicestershire LE11 3TU, UK. email: h.rahnejat@lboro.ac.uk
}

ring's inner rim equates the integrated contact pressure distribution on its load bearing surface within the cylinder bore. The contact pressures are ideally generated by a lubricant film of sufficient thickness to inhibit direct surface-to-surface contact (i.e. fluid film lubrication). However, this condition is not satisfied at all times during the engine cycle such as at the dead centres, where motion reversals take place $[8]$, resulting in a mixed regime of lubrication. In the vicinity of the top dead centre a higher combustion force can contribute to an increased contact force. At the bottom dead centre and during strokes other than power-stroke, the contact force is quite low and, with momentary cessation of entraining motion, boundary interactions are prevalent. In such instances any reduced friction from direct boundary interactions is entirely due to lubricant entrapment by squeeze film action [9] and by non-Newtonian behaviour of very thin adsorbed films at the tips of asperity pairs $[\mathbf{2}, \mathbf{1 0}-$ 12]. Therefore, a detailed analysis should account for non-Newtonian frictional characteristics of the contact, as well as local deformation of surfaces and squeeze film action (i.e. a transient analysis). Finally, with very few exceptions [10] there is a dearth of comparative work between predictions and experimental measurements. 
Table 1 Engine and lubricant specifications

\begin{tabular}{ll}
\hline Physical-geometrical details & Value \\
\hline Nominal diameter (mm) & 96 \\
Axial width (mm) & 1 \\
Ring radial depth (mm) & 3 \\
Modulus of elasticity (GPa) & 203 \\
Poisson's ratio & 0.23 \\
Moment of inertia of the ring (m $\left.{ }^{4}\right)$ & $4.06 \times 10^{-12}$ \\
Engine operating speed (r/min) & 13000 \\
Max. combustion pressure (Bar) & 120 \\
Lubricant dynamic viscosity at & 0.004 \\
$\quad$ atmospheric pressure (Pa s) & $10^{-8}$ \\
Piezo-viscosity index, $\alpha\left(\mathrm{Pa}^{-1}\right)$ & \\
\hline
\end{tabular}

This paper presents transient analysis of piston compression ring-to-bore contact for the entire cycle of four-stroke IC engines. The analysis includes ring-to-bore conformability, two-dimensional elastohydrodynamics of a rough, globally deformed ring for its radial in-plane behaviour, and non-Newtonian frictional behaviour of very thin interrupted films. It omits the out-of-plane deformation of the ring as well as any of its rigid body motions in twist and flutter. This initial analysis is isothermal. However, the important effect of friction generated heat on lubricant effective viscosity and thermal distortion of the bore and ring are acknowledged, both of which motivate future developments of the model. The current model is validated against measurements of friction by other research workers [13], showing good conformance.

\section{ANALYSIS OF RING SHAPE IN AN OUT-OF-ROUND BORE}

\subsection{Ring-bore conformability}

The role of a piston compression ring is sealing for effective compression and reduced blow-by. Hence, the conformability of ring-liner conjunction is an important part of any analysis. An early attempt to determine conformability was made by Hill and Newman [4], who included gas pressure and ring tension. However, they assumed a constant circumferential elastic pressure due to ring tension, which is clearly not a valid assumption as pointed out by Okamoto and Sakai [5]. Bore conformability given by Hill and Newman [4] was later used by Ma et al. [1] in their analysis of ring-pack lubrication. The non-circularity of the bore cross-section was taken into account in the estimation of ring-bore gap, which forms a part of the lubricant film thickness. This gap includes the ring conformability to a bore approximated by an $n$ thorder polynomial, which includes gas loading both in front and at the back of the ring. Further work on oil availability and frictional losses was estimated for different bore out-of-roundness values. The bore shape was described by a Fourier series by Loenne and Ziemba [14].
The current method consists of measuring the bore radius with a coordinate measuring machine (CMM), having a repeatability of $1.5 \mu \mathrm{m}$. Then, an iteration process is employed for the prediction of bore order through estimation of an incomplete ring residual end-gap when fitted in situ within the cylinder. An example engine is used for the purpose of model development, but the procedure is equally valid for any configuration. The engine concerned is a single-cylinder gasoline engine from a motocross motorcycle, with a maximum speed of $13000 \mathrm{r} / \mathrm{min}$ and a maximum power of $50 \mathrm{bhp}$. The engine is fitted with a wet liner made of special grade aluminium, coated with Nikasil. All other relevant specifications are listed in Table 1. A typical measured bore is shown in Fig. 1(a). The needle-shaped stylus of the CMM was set at the speed of $50 \mathrm{~m} / \mathrm{min}$, measuring bore radii at 1020 points along its various circumferential positions (Fig. 1(b)). The dotted line represents the actual measurements, while the full line is the line of best rms fit. The same procedure is also carried out for the fitted compression ring. The results are presented as a polar plot in Fig. 2 .

The specifications for the compression ring are given in Table 2 . It is very important to accurately replicate ring geometry in tribological studies, discussed

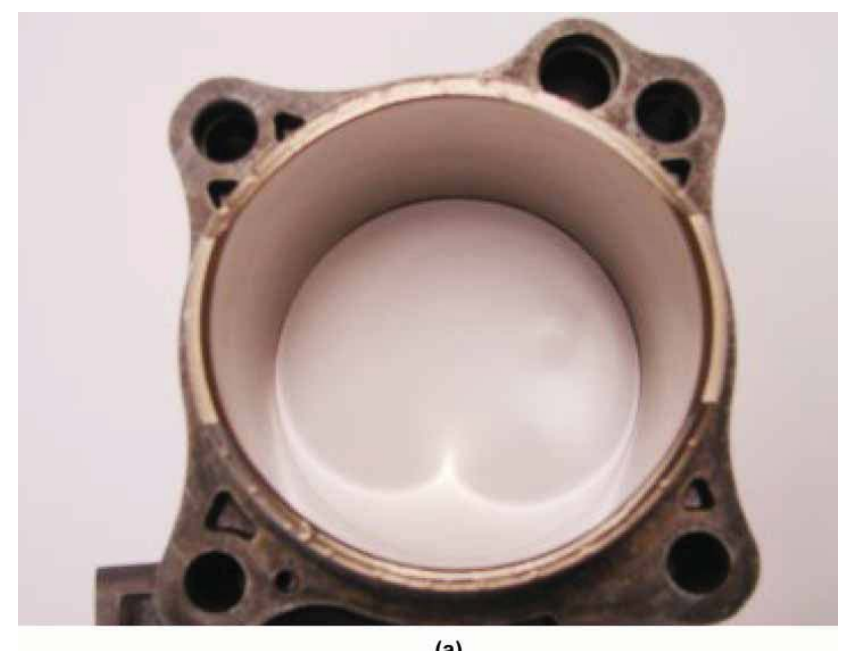

(a)

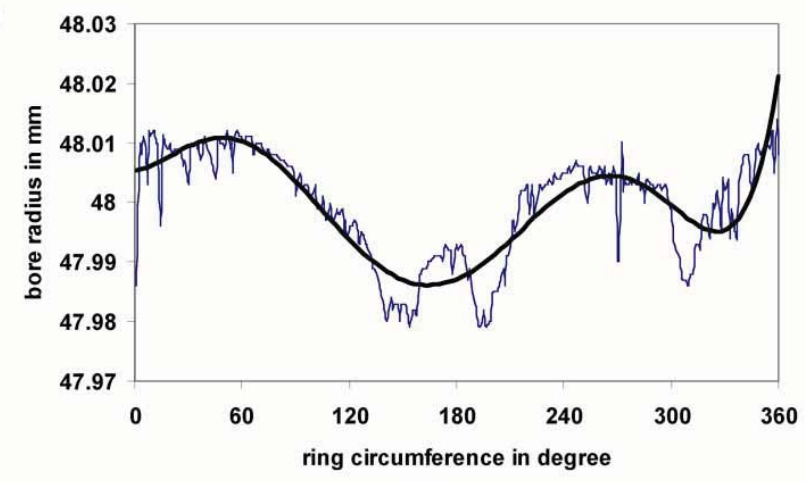

(b)

Fig. 1 Bore out-of-roundness: (a) cylinder bore under measurement and (b) measured bore profile 


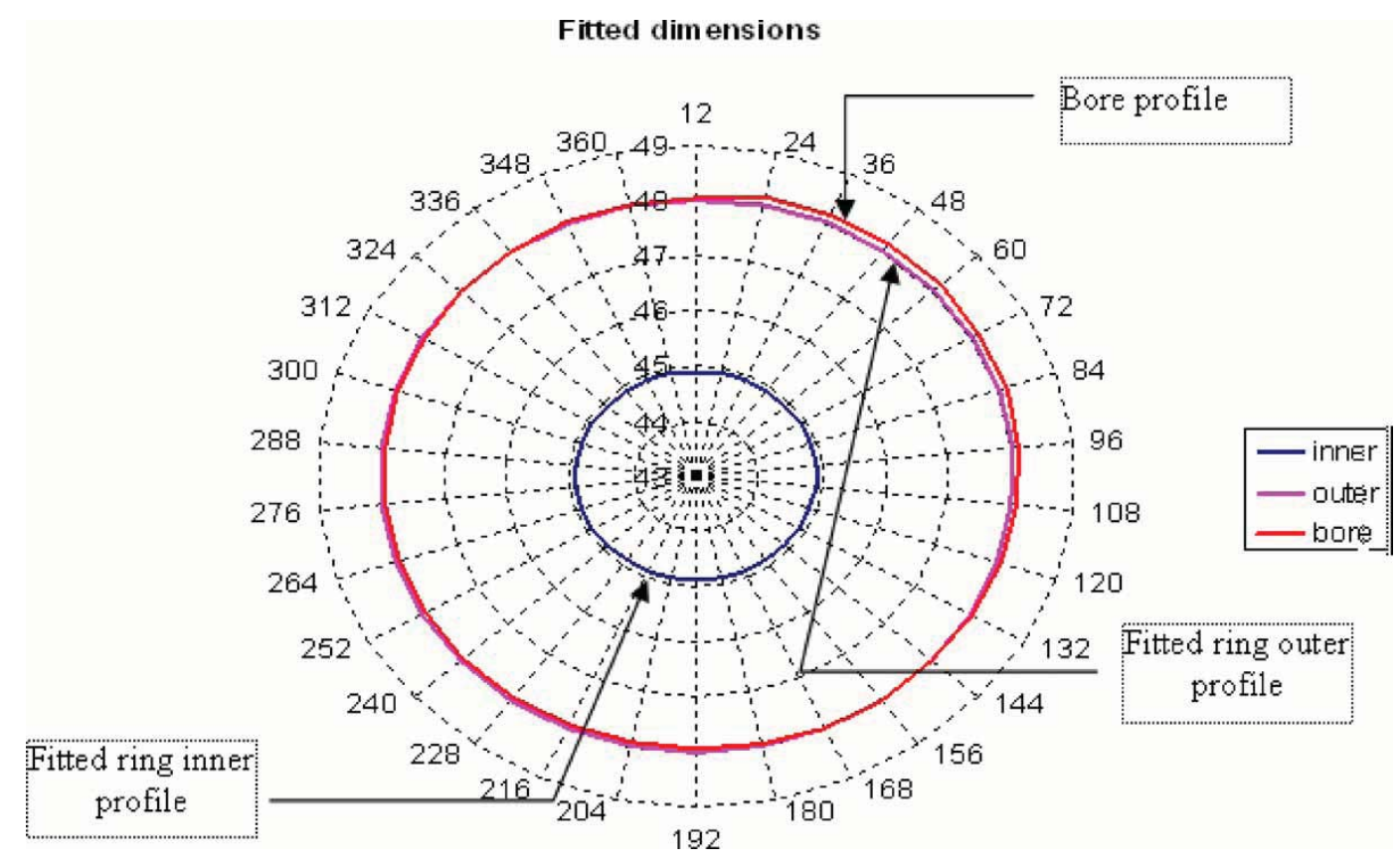

Fig. 2 Polar plot of measured ring-bore fit

later. Various attempts have been made to represent ring profile accurately such as that by Akalin and Newaz [10], who presented the profile of a compression ring used for assessment of friction by Furuhama and Sasaki [13] using a floating liner. The approximated profile was based on its outer machined surface. Validation of the current work is also presented later against the same measurements, but the profile suggested by Akalin and Newaz [10] lead to convergence difficulties with numerical models. This is because a converging-diverging conjunction is needed to solve the Reynolds equation. A ring having a flat central profile (Fig. 3(a)) presents multiple gap minima, which in turn leads to difficulties in lubricant entrainment and can promote back-flow. Therefore, a ring profile similar to that suggested by Ma et al. [1] (Fig. 3(b)) is adopted here.

The shape of the ring in Fig. 3(b) is approximated by a parabola, thus

$$
s_{i j}=\frac{x_{i j}^{2} \Delta_{i j}}{(0.5 b)^{2}}
$$

Table 2 Ring specifications

\begin{tabular}{ll}
\hline Parameter details & Value \\
\hline Number of nodes in ring axial direction & 200 \\
Number of nodes along ring circumference & 180 \\
Ring axial width (mm) & 1.0 \\
Ring radial depth (mm) & 3.0 \\
Cylinder bore diameter (mm) & 96.0 \\
Ring modulus of elasticity (GPa) & 203 \\
Second area moment of inertia of the ring $\left(\mathrm{m}^{-4}\right)$ & $4.06 \times 10^{-12}$ \\
\hline
\end{tabular}

This provides an elastic film shape of

$$
h_{i j}=h_{0}+s_{i j}+\delta_{i j}+\Delta_{i j}
$$

where $\Delta_{i j}$ is the in-plane global deformation of the ring, while in situ, $\delta_{i j}$ is the localized deformation due to the generated lubricant pressures, and $h_{0}$ is the nominal clearance.

Based on the original work of Hill and Newman [4], Ma et al. [1] defined a conformability factor for a ringliner system, including the effect of gas pressure and ring elasticity as

$$
\xi_{n}=\frac{3\left(F_{\mathrm{e}}+F_{\mathrm{g}}\right) R_{\mathrm{b}}^{2}\left(2 R_{\mathrm{b}}-\kappa\right)^{2}}{2 \pi E_{\mathrm{r}} R_{0} b \kappa^{3}\left(n^{2}-1\right)^{2}}
$$

The outward elastic force $F_{e}$ is due to ring relaxation, while fitted inside the bore. However, Ma et al. [1] considered $F_{\mathrm{e}}$ to be constant. In the current analysis variation in elastic pressures generated on the ring circumference is taken into account (section 2.2).

The gas force $F_{\mathrm{g}}$ is due to the net gas pressure acting on the ring. The combustion gas exerts pressure from either side (back and front) of the ring (Fig. 4). On the back of the ring, the gas pressure is assumed to be the combustion pressure. On the front of the ring, the net pressure is the difference between that of combustion and the crank case. The pressure on the front side is given as

$$
P_{\mathrm{gf}}(\theta)=P_{t}+\left(P_{1}-P_{\mathrm{t}}\right) \frac{x_{\mathrm{in}}(\theta)+x_{\mathrm{c}}(\theta)}{2 b}
$$

Hence the net force due to gas pressure is

$$
F_{\mathrm{g}}=b\left(P_{\mathrm{gb}}-P_{\mathrm{gf}}\right)
$$




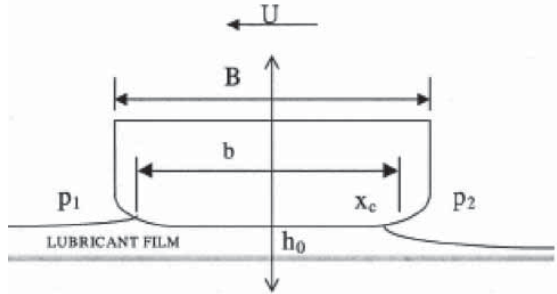

(a)

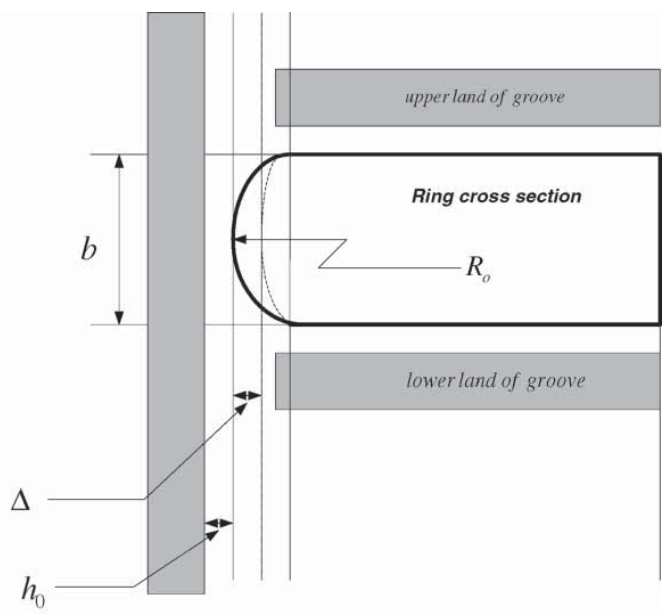

(b)

Fig. 3 Ring profile: (a) after Akalin and Newaz [10] and (b) in the current analysis

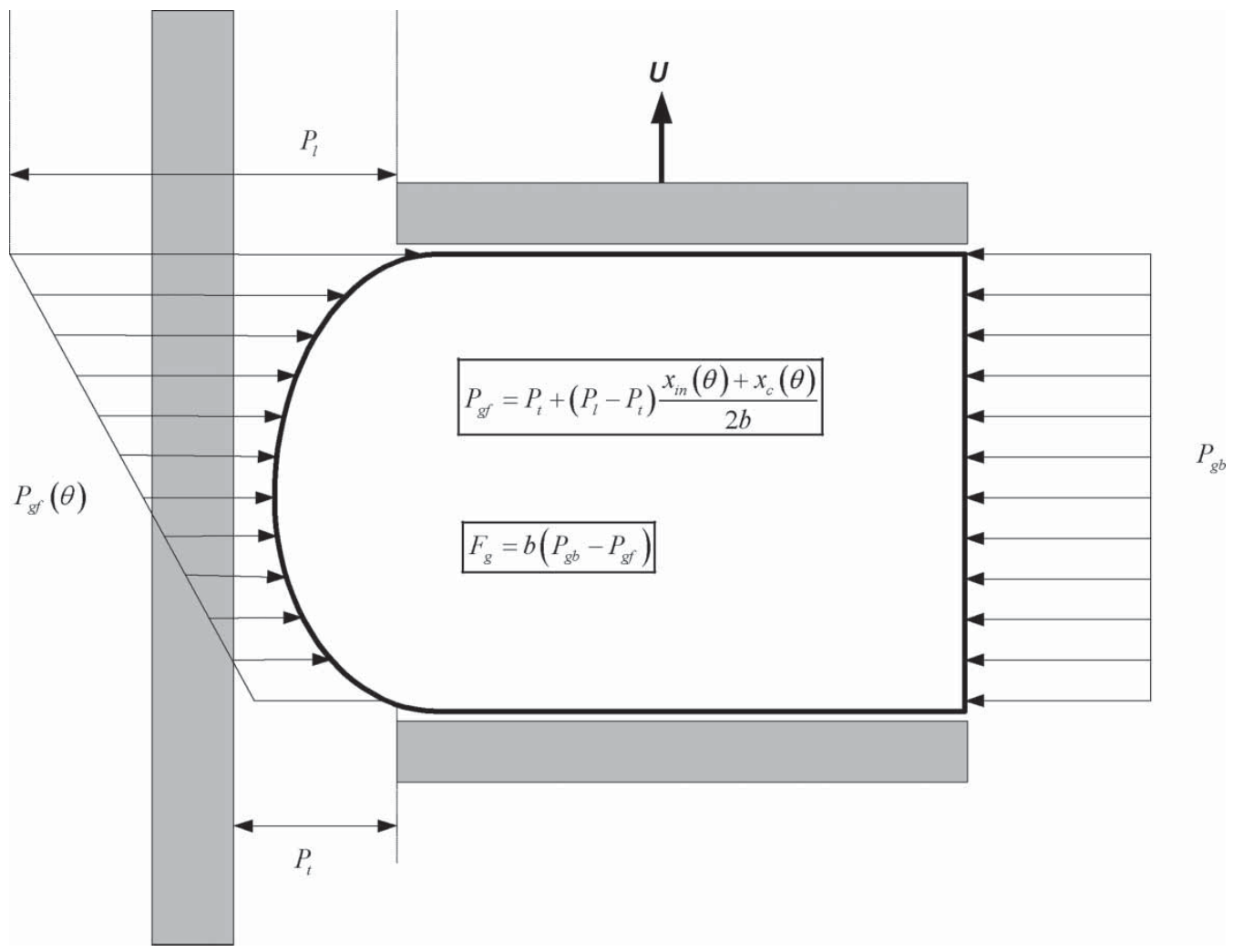

Fig. 4 Applied pressures around the ring

The crank case pressure is taken to be at ambient in this analysis. At the leading edge of the ring combustion pressure operates, while at its trailing edge pressure is that of the crank-case. In the suction and power strokes, the combustion pressure acts on the trailing edge of the ring and the leading edge pressure is that of the crank-case. For an assumed order of the bore, the gap between the ring-bore is found as

$$
\Omega(\theta)=\Delta R_{\mathrm{a}}(\theta)-\xi_{n}(\theta) \quad \text { for } \quad \Delta R_{\mathrm{a}}(\theta)>\xi_{n}(\theta)
$$

or

$$
\Omega(\theta)=0 \quad \text { for } \quad \Delta R_{\mathrm{a}}(\theta) \leqslant \xi_{n}(\theta)
$$


Now the gap in equation (4) is calculated, commencing from the initial assumption of a second-order bore, when the value of $F_{\mathrm{e}}$ is known (see section 2.2).

\subsection{Calculation of the elastic force due to global radial ring deformation}

Okamoto and Sakai [5] and Mishra et al. [8] estimated the generated elastic contact pressures when a ring is fitted into the cylinder bore. The ring is considered as a beam element, fixed at one end and subjected to an applied bending moment. The correct pressure distribution is considered to be that which would result in stable sealing. The bending moment at a point $i$ is obtained due to an applied load $Q_{j}$ at a point $j$ as (Fig. 5)

$$
M\left(\theta_{i}, \alpha_{j}\right)=Q_{j} R_{0} \sin \left(\theta_{i}+\alpha_{j}\right)
$$

In the analysis many such forces $Q_{j}$ act at elements $j$, the total effect of which is the applied elastic force.

Substituting for the bending moment yields the radial global deformation, $\Delta$ is required for determination of the elastic film shape in equation (2) [8]

$$
\begin{aligned}
\Delta\left(\theta_{i}, \alpha_{j}\right)=\Delta_{i j}= & \frac{R_{0}^{3} Q_{j}}{E_{\mathrm{r}} I} \cos \alpha_{j} \sin \theta_{i}\left(\frac{1}{2} \sin ^{2} \theta_{i}\right) \\
& +\cos \alpha_{j} \sin \theta_{i}\left(\frac{1}{4} \sin 2 \theta_{i}+\frac{\theta_{i}}{2}\right) \\
& -\cos \alpha_{j} \cos \theta_{i}\left(\frac{\theta_{i}}{2}-\frac{1}{4} \sin 2 \theta_{i}\right) \\
& -\sin \alpha_{j} \cos \theta_{i}\left(\frac{1}{2} \sin ^{2} \theta_{i}\right)
\end{aligned}
$$

The elastic pressure on the ring face-width $b$ due to this deformation is

$$
P_{\mathrm{e}_{i j}}=\frac{\mathrm{EI}}{2 \pi a_{i, j} b R_{0}^{4}} \Delta_{i, j}
$$

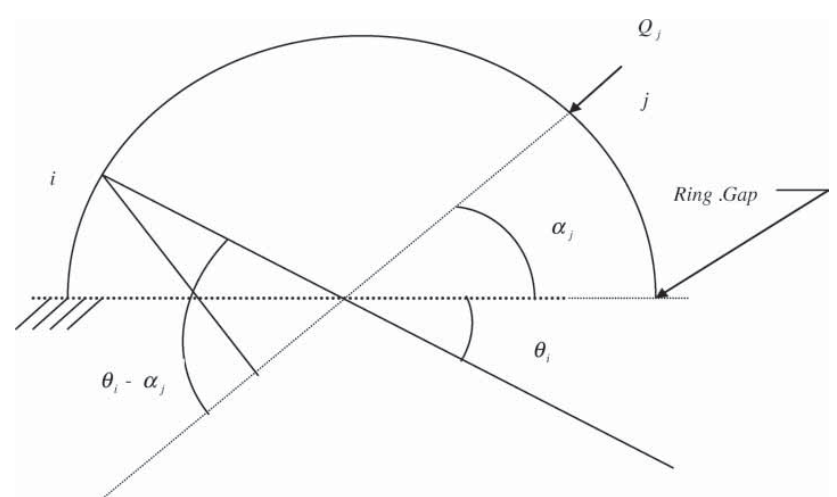

Fig. 5 Ring as a beam element subject to in-plane deformation

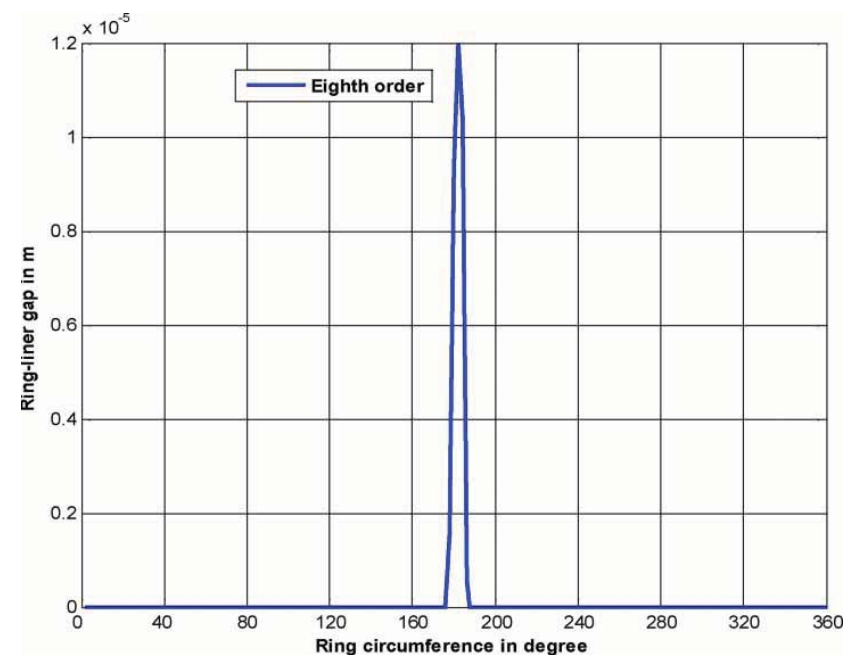

Fig. 6 Ring-bore gap (conformability)

Thus, the elastic force acting outward on the ring is

$$
F_{\mathrm{e}}=\iint p_{\mathrm{e}_{i j}} \mathrm{~d} x \mathrm{~d} y
$$

\subsection{Result of deformed ring-to-out-of-round bore conjunction}

An iterative solution to equations (3), (5), (6), and (10), commencing with an assumption of an initial second-order bore shape provides the global radially deformed ring shape, $\Delta_{i j}$, and the corresponding ringbore (liner) gap, $\Omega(\theta)$. Figure 6 shows the gap shape, when an eighth-order bore fit is used. Note that the maximum error is found to be around $1 \mu \mathrm{m}$ at the position of the ring end-gap. This means a good degree of conformance is found.

\section{TRIBOLOGY OF RING-BORE CONJUNCTION}

\subsection{Fluid film viscous action}

The motion of the ring results in the entrainment of lubricant into the ring-bore conjunction. The generated pressures form a film of lubricant by hydrodynamic action. This is the elastic film shape, given by equation (2) and shown in Fig. 3(b). The film thickness and the corresponding pressure distribution are obtained at any instant of time with the simultaneous solution of equation (2) and Reynolds equation

$$
\begin{aligned}
\frac{\partial}{\partial x} & \left(\frac{\rho h^{3}}{\eta} \frac{\partial p_{\mathrm{h}}}{\partial x}\right)+\frac{\partial}{\partial y}\left(\frac{\rho h^{3}}{\eta} \frac{\partial p_{\mathrm{h}}}{\partial y}\right) \\
& =12\left(U \frac{\partial}{\partial x}(\rho h)+V \frac{\partial}{\partial y}(\rho h)+\frac{\partial}{\partial t}(\rho h)\right)
\end{aligned}
$$

where the instantaneous contact kinematics determines: $U=(1 / 2) \dot{x}$ ( $\dot{x}$ being the sliding velocity of the 
ring), $V=0$ (no side-leakage of lubricant in the circumferential contact direction), and the squeeze film action is obtained as: $\left(\partial h_{i j} / \partial t\right) \approx\left(\Delta h_{i j} / \Delta t\right)=\left(h_{i j}^{k}-\right.$ $\left.h_{i j}^{k-1}\right) / \Delta t$ (first-order approximation and $\partial \rho / \partial t=0$ ). Note that for the approaching contiguous surfaces in contact $\partial h_{i j} / \partial t<0$.

Simultaneous solution of equations (2) and (11) requires the determination of the bulk rheological state of the lubricant in the contact. In the isothermal analysis presented here, these are given as:

For lubricant viscosity's pressure-dependence [15]

$$
\bar{\eta}=\frac{\eta}{\eta_{0}}=\exp ^{\left(\ln \eta_{0}+9.67\right)\left(-1+\left(1+5.1 \times 10^{-9} p_{\mathrm{h}}\right)\right)}
$$

For lubricant density's pressure-dependence [16]

$$
\bar{\rho}=\frac{\rho}{\rho_{0}}=1+\frac{0.6 p_{\mathrm{h}}}{1+1.7 p_{\mathrm{h}}}
$$

When the generated pressures are sufficiently large, localized deformation of the contiguous surfaces may also take place $\left(\delta_{i j}\right.$ in equation (2)). This is obtained through use of generalized contact elasticity integral as

$$
\delta_{i, j}=\frac{p_{\mathrm{h}_{i j}}}{\pi E^{\prime}} \mathbf{D}^{*}
$$

where the influence coefficient matrix $\mathbf{D}^{*}$ is given by Balakrishnan and Rahnejat [9] (see Appendix 2), and: $1 / E^{\prime}=1 / 2\left[\left(1-v_{\mathrm{r}}^{2}\right) / E_{\mathrm{r}}+\left(1-v_{\mathrm{b}}^{2}\right) / E_{\mathrm{b}}\right]$.

Mishra et al. [8] provide a series of quasi-static step solutions for the reversal at the top dead-centre, using equations (2), (8), and (11) to (14) with boundary conditions:

A fully flooded inlet: $p_{\mathrm{h}}=0$ at $x=-\infty$, and Reynolds exit boundary condition $p_{\mathrm{h}}=\mathrm{d} p_{\mathrm{h}} / \mathrm{d} x=0$ at $x=x_{c}$. Two main shortcomings remain.

First, observations show that in piston reversals at the dead centres due to momentary cessation of entraining motion $(U=0)$ and insignificant squeeze film motion $(\partial h / \partial t \approx 0)$, formation of a coherent lubricant film is not assured (note the right-hand side of Reynolds equation $\rightarrow 0$ ). Thus, direct surfaceto-surface contact through asperity interactions can occur. This leads to a mixed regime of lubrication (an interrupted fluid film).

Second, lubricant viscosity is reduced with rising contact temperatures at high shear rates, particularly at high sliding velocities, typical of high performance engines. Due to quite thin films in the compression ring-bore conjunction, heat removal takes place mainly by conduction through the contacting bodies, which in the case of the ring can cause further global thermoelastic distortion.

The current analysis extends the work of Mishra et al. [8] by including an asperity interaction model, but still retains the isothermal assumption.

\subsection{Asperity interactions}

With an insufficient film of lubricant, asperity interactions occur between any pair of rough surfaces in close contiguity. Greenwood and Tripp [17] proposed a model to obtain the pressure distribution between two rough surfaces with normally distributed asperity heights

$$
p_{\text {asp }}=K^{*} E^{\prime} F_{2.5}(\lambda)
$$

The surface roughness of both the ring and the bore are assumed to be isotropic.

The function $F_{2.5}(\lambda)$ relates to the probability distribution of asperity heights. For a Gaussian distribution of asperities, $F_{2.5}(\lambda)$ has the following form [18]

$$
F_{2.5}(\lambda)=\frac{1}{\sqrt{2 \pi}} \int_{\lambda}^{\infty}(s-\lambda)^{5 / 2} e^{s^{2} / 2} \mathrm{~d} s
$$

A curve-fit of the function is more suited to numerical analysis. For typical ring-bore contact Hu et al. [18] state that

$$
F_{2.5}(\lambda)= \begin{cases}A(\beta-\lambda)^{z} & \lambda \leqslant \beta \\ 0 & \lambda>\beta\end{cases}
$$

where $\beta=4, A=4.4068 \times 10^{-5}, z=6.804$, and $\lambda=$ $h / \sigma_{\text {rms }}$ (Stribeck's oil film parameter). $K^{*}$ in equation (15) is a function of the surface roughness as $K^{*}=$ $5.318748 \times 10^{10} \sigma_{\text {rms }}^{5 / 2}$.

The generated contact pressures are, therefore, due to viscous action of the fluid (hydrodynamic/elastohydrodynamic) and the asperity contact pressures. At any instant of time in the engine cycle, the applied force acting on the ring-bore conjunction is obtained as

$$
F=F_{\mathrm{e}}+F_{\mathrm{g}}
$$

where $F_{\mathrm{g}}$ is given by equation (5) and $F_{\mathrm{e}}$ by equation (10). This force should equate the integrated pressure distribution arising from generated hydrodynamic and asperity pressures

$$
W=\iint p \mathrm{~d} x \mathrm{~d} y
$$

where $p=p_{\mathrm{h}}+p_{\text {asp }}$.

\subsection{Conjunctional friction}

Balakrisnan and Rahnejat [9] and Mishra et al. [8] ignored the effect of friction, while Ma et al. [1] only considered viscous friction. In reality, generated friction depends on the prevailing regime of lubrication which alters during the four strokes of the engine cycle, according to contact kinematics and conjunctional load. 
Viscous friction is due to generated shear stress arising from entraining motion of the lubricant as well as pressure gradient in a converging-diverging wedge as

$$
\tau_{i j}=\frac{h_{i j}}{2} \frac{\partial p_{\mathrm{h}}}{\partial x}+\frac{\eta_{i j} U}{h_{i j}}
$$

where it is assumed that $\left(\partial p_{\mathrm{h}} / \partial x\right) \gg\left(\partial p_{\mathrm{h}} / \partial y\right)$. In fact, the pressure induced shear in partially conforming contacts such as the ring-bore conjunction is much smaller than that due to the entraining motion of the fluid. However, both effects are included in the current analysis, except for the cavitation region, where the first term in equation (20) is ignored. Thus, viscous friction becomes

$$
f_{\mathrm{v}}=\iint \tau_{i j} \mathrm{~d} x \mathrm{~d} y
$$

Asperity friction force can simply be determined if a coefficient of friction can be stated

$$
f_{\text {asp }}=\mu_{\text {asp }} \iint p_{\text {asp }} \mathrm{d} x \mathrm{~d} y
$$

For ring-bore asperity interactions, a coefficient of friction in the range $0.1-0.15$ is suggested by Bolander et al. [2].

Therefore, the total friction force is

$$
f=f_{\mathrm{v}}+f_{\text {asp }}
$$

\subsection{Method of solution}

The following step-wise procedure is used for the ringbore conjunction at any instant of time during the engine cycle

Step 1: The gas force $F_{\mathrm{g}}$ is obtained as the instantaneous combustion pressure (Fig. 7) acting over the crown surface area of the piston: $F_{\mathrm{g}} \approx p_{\mathrm{g}} / \pi R_{\mathrm{b}}^{2}$.

Step 2: The sliding velocity of the ring relative to the bore is an input kinematic condition. This means that any ring flutter, twist, or tilt is not taken into account.

Step 3: The in-plane global deformation of the ring $\Delta_{i j}$ and the net elastic force $F_{\mathrm{e}}$ are obtained from equations (8) and (10).

Step 4: The rigid gap $h_{0}$ is initially considered to be the same as the nominal ring-bore clearance.

Step 5: Equations (2) and (11) to (14) are solved simultaneously in order to obtain the film shape $h_{i j}$ and the corresponding pressure distribution $p_{\mathrm{h}_{i j}}$. Note that all negative pressures are discarded according to Reynolds exit boundary conditions.

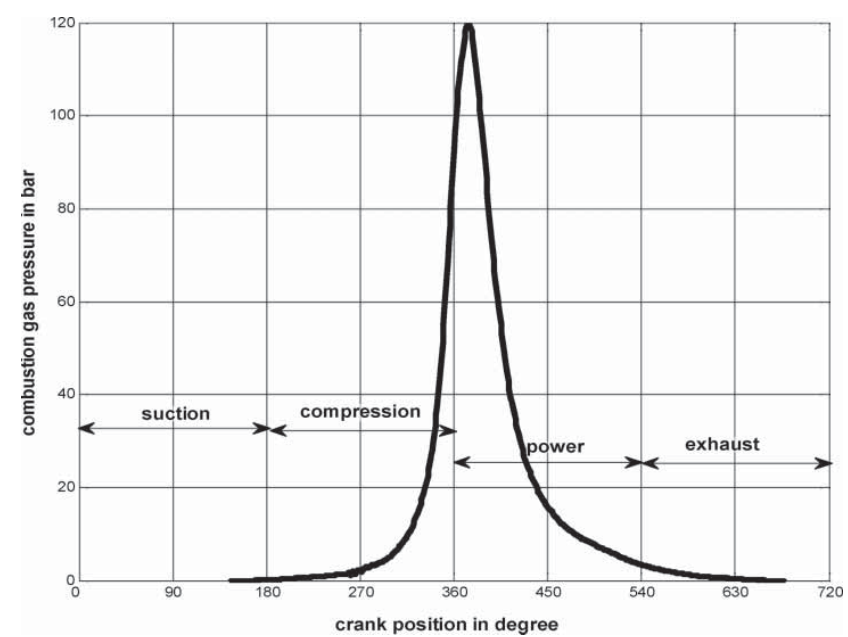

Fig. 7 Measured combustion pressure

Step 6: The following pressure convergence criterion is used

$$
\frac{\sum_{i}^{l} \sum_{j}^{\mathrm{m}}\left|p_{\mathrm{h}_{i, j}}^{k+1}-p_{\mathrm{h}_{i, j}}^{k}\right|}{\sum_{i}^{\mathrm{l}} \sum_{j}^{\mathrm{m}}\left|p_{\mathrm{h}_{i, j}}^{k+1}\right|} \leqslant 0.02
$$

If the criterion is not met, pressure relaxation is applied as $p_{h_{i, j}}^{k+1}=p_{h_{i, j}}^{k}+\Psi\left(p_{h_{i, j}}^{k+1}-p_{h_{i, j}}^{k}\right)$ and Steps 5 and 6 are repeated. $\Psi$ is an under-relaxation factor in the range $0.3-0.7$.

Step 7: Values of $\lambda_{i j}=\left(h_{i j} / \sigma_{\text {rms }}\right)$ are obtained. Then equations (15) and (17) are used to determine the asperity pressure distribution $p_{\text {asp }}{ }_{i j}$.

Step 8: Contact load is calculated as the integrated conjunctional total pressure distribution, using equation (19).

Step 9: The contact load should balance the applied load at any instant of time. Thus, the following load convergence criterion is employed: $|F-W / F| \leqslant 0.01$. If this condition is not satisfied the rigid clearance is altered as $h_{0}^{k}=h_{0}^{k-1}-\{\vartheta|F-W / F|\}$. The Steps 5 to 9 are then repeated. $\vartheta$ is within the range $10^{-9}-10^{-8}$.

Note that any moment loading of the ring-bore contact due to tilt of the piston, twist or out-of-plane motions of the ring are not taken into account in the present analysis.

Step 10: Conjunction friction is determined, using equation (23).

\section{RESULTS AND DISCUSSION}

\subsection{Predictions for the high performance motor sport engine}

For an engine cycle, tribological analysis of ring-bore contact is undertaken. The required inputs to the simulation are the combustion pressure (Fig. 7) and the 
sliding velocity of the ring relative to the bore surface (Fig. 8). Note that the speed of lubricant entrainment is half this sliding velocity. Motion reversals occur at the top and bottom dead centres, indicated by the crank-angle positions $0^{\circ}, 360^{\circ}$, and $720^{\circ}$ for the former and $180^{\circ}$ and $540^{\circ}$ for the latter during the indicated strokes, respectively. There is no speed of entraining motion of the lubricant into the contact at these locations (reversal points).

Figure 9 shows the applied contact load as the result of combined gas pressure and ring tension (i.e. the total contact load). A logarithmic vertical axis is chosen in order to provide a clearer picture of the large transient variations. The contact load is significant in the region $340^{\circ}-380^{\circ}$ (reversal at the top dead centre: transition from compression to power strokes) with its maximum value of $6000 \mathrm{~N}$ (logarithmic value of 3.78) at $373^{\circ}$ (maximum combustion pressure, Fig. 7). Worst tribological conditions often occur at high loads and low speeds of entraining motion. Hence, Figs 8 and 9 show the reason behind poor ring-bore lubrication

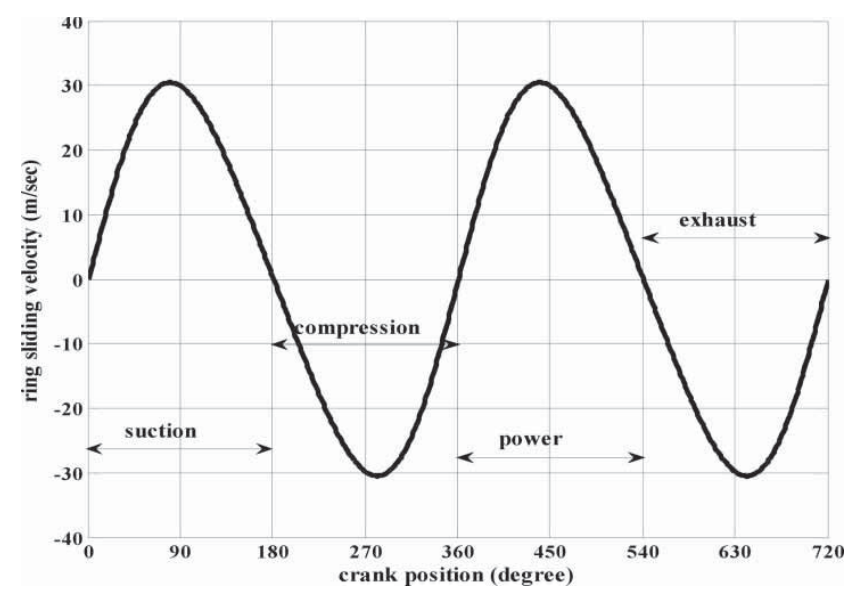

Fig. 8 Sliding velocity of the ring relative to the bore

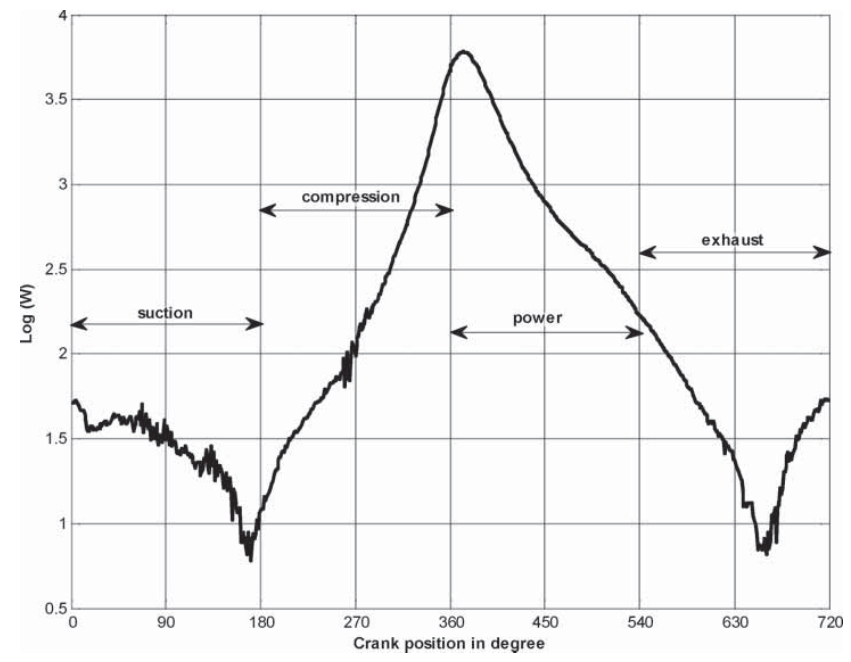

Fig. 9 Variation of contact load in the vicinity of the top dead centre. With high load and low speed of entraining motion greater asperity interactions occur. Figure 10 shows the variation of the minimum film thickness during a complete cycle. The least film thickness occurs at the reversals at the beginning and at the end of the power stroke. These are fractions of a micrometer, leading to increased boundary friction contributions during the reversals. In fact $\sigma_{\text {rms }}=0.65 \mu \mathrm{m}$ for the case reported here. This means that for a considerable part of the cycle and particularly during the power stroke some asperity interactions occur, thus increasing friction. This is evident in Fig. 11(a), showing contribution of boundary interactions to the overall friction mainly during the reversals and particularly in transition to or from the power stroke. Note that upward motion of the piston (towards the top dead centre) is considered as positive in the figure, thus negative values indicate opposing downward action of friction. Figure 11(b) shows the contribution of viscous friction. Both boundary and viscous friction reverse at the dead centres, where cessation of motion yields zero friction. With rising sliding velocity viscous contribution increases, while resulting thicker oil films diminishes the asperity interactions, thus reduces boundary friction. The total friction is addition of contributions made through viscous shear and asperity interactions. Figure 11(c) shows the total friction force.

\subsection{Prediction of frictional losses for the single-cylinder motor sport engine}

Reduction of frictional losses is a primary objective in development of advanced cylinder liners, which are often coated, etched, and honed as described by Etsion [11], Rahnejat et al. [19], and Gohar and Rahnejat [20]. The surface modifications are quite expensive

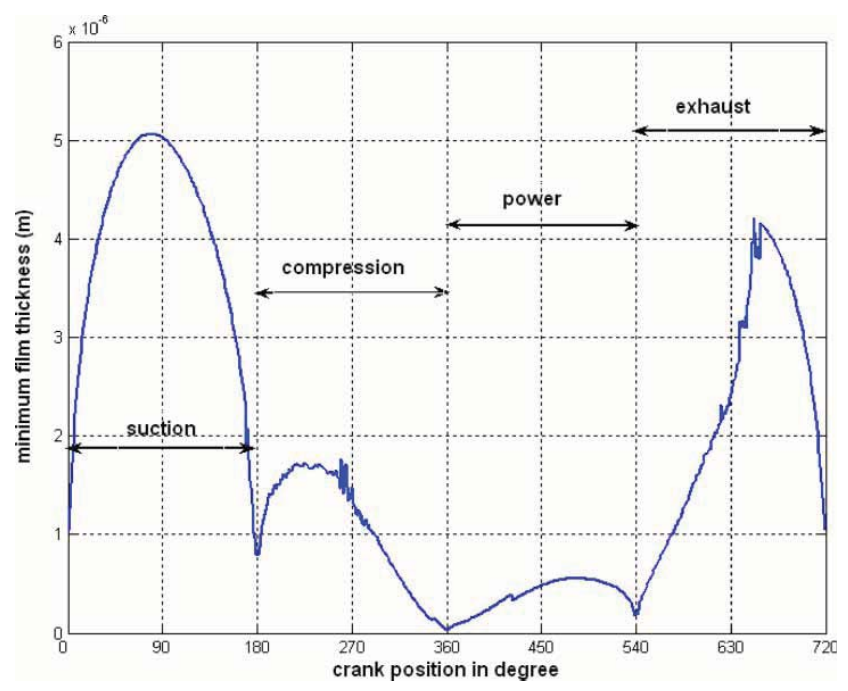

Fig. 10 Minimum film thickness variation in an engine cycle 


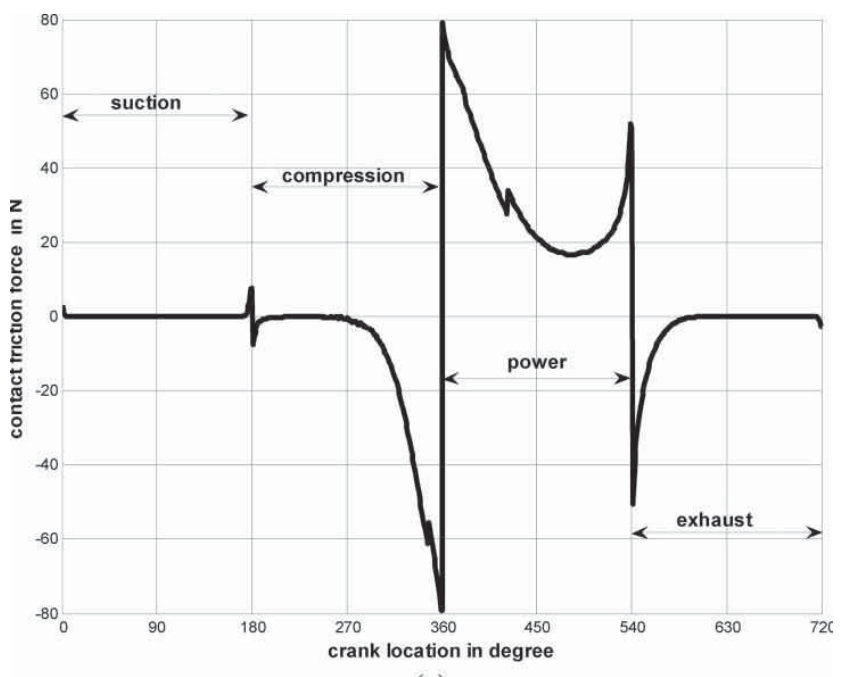

(a)

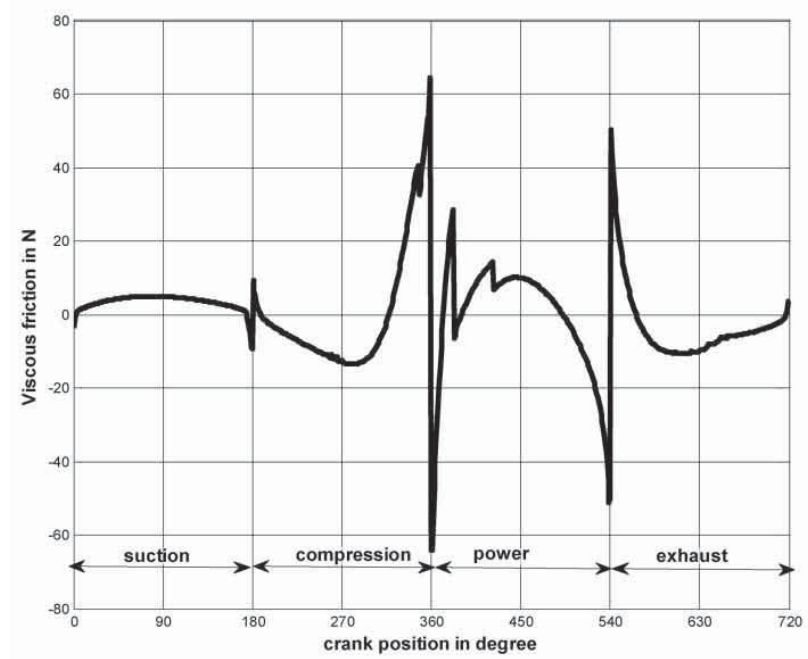

(b)

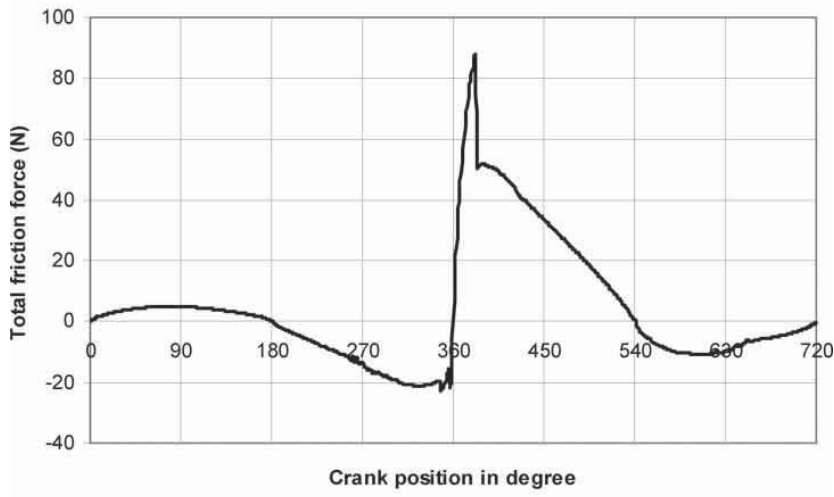

(c)

Fig. 11 Transient state of friction during the engine strokes: (a) asperity contact friction force, (b) viscous friction force, and (c) total friction force

and currently used in high performance racing vehicles such as for Le Mans races and in Formula 1. The high costs and the transient nature of power losses point to greater use of predictive methods.
Figure 12 shows the transient nature of frictional power losses for ring-liner conjunction during the piston strokes. In the suction stroke frictional power losses increase up to the crank-angle of $90^{\circ}$ (midspan). It reaches a maximum value of $200 \mathrm{~W}$. Thereafter it decreases and diminishes at the crank-angle of $180^{\circ}$ (bottom dead centre). This indicates that during suction, with low contact load (Fig. 9) the main contribution to losses is due to viscous shearing of the lubricant. In the subsequent compression stroke a similar trend is noted. In the power stroke in $360^{\circ}$ $<$ crank-angle $<373^{\circ}$, there is a sharp rise in power loss, with significant contribution due to asperity interactions, because of diminished film thickness (Fig. 10). The drop at the maximum combustion pressure is due to momentary localized contact deformation. This is not sustained due to the reducing contact pressures and increasing sliding velocity thereafter. The combination of increased load and thin film causes the largest frictional losses in power stroke until the bottom dead centre is reached. The subsequent exhaust stroke exhibits similar characteristics to the suction and compression strokes. Nearly half the overall losses occur in the power stroke. It is clear that the losses can be reduced by surface modification at the reversals with low speeds of entraining motion and reduced film thickness. These modifications take the form of etchings on the cylinder bore or liner to retain small reservoirs of lubricant [19].

\subsection{Model validation}

Furuhama and Sasaki [13] modified a V8 Chevrolet engine to a form a V2 configuration. Cylinder 8 was furnished with a floating liner, while cylinder 7 was left for balancing purposes. The engine bores are $94.89 \mathrm{~mm}$ with piston stroke of $88.39 \mathrm{~mm}$

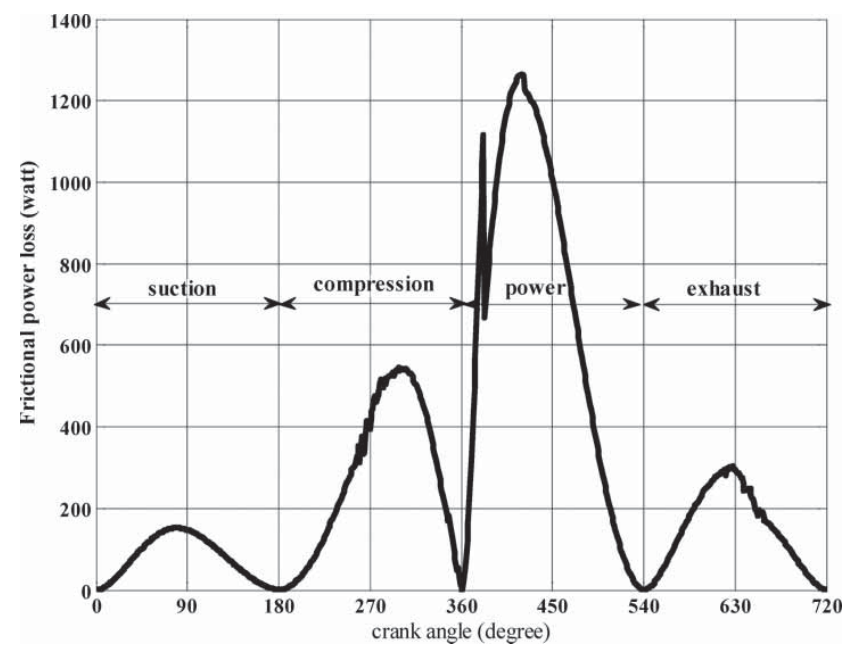

Fig. 12 Transient predicted parasitic losses in an engine cycle 


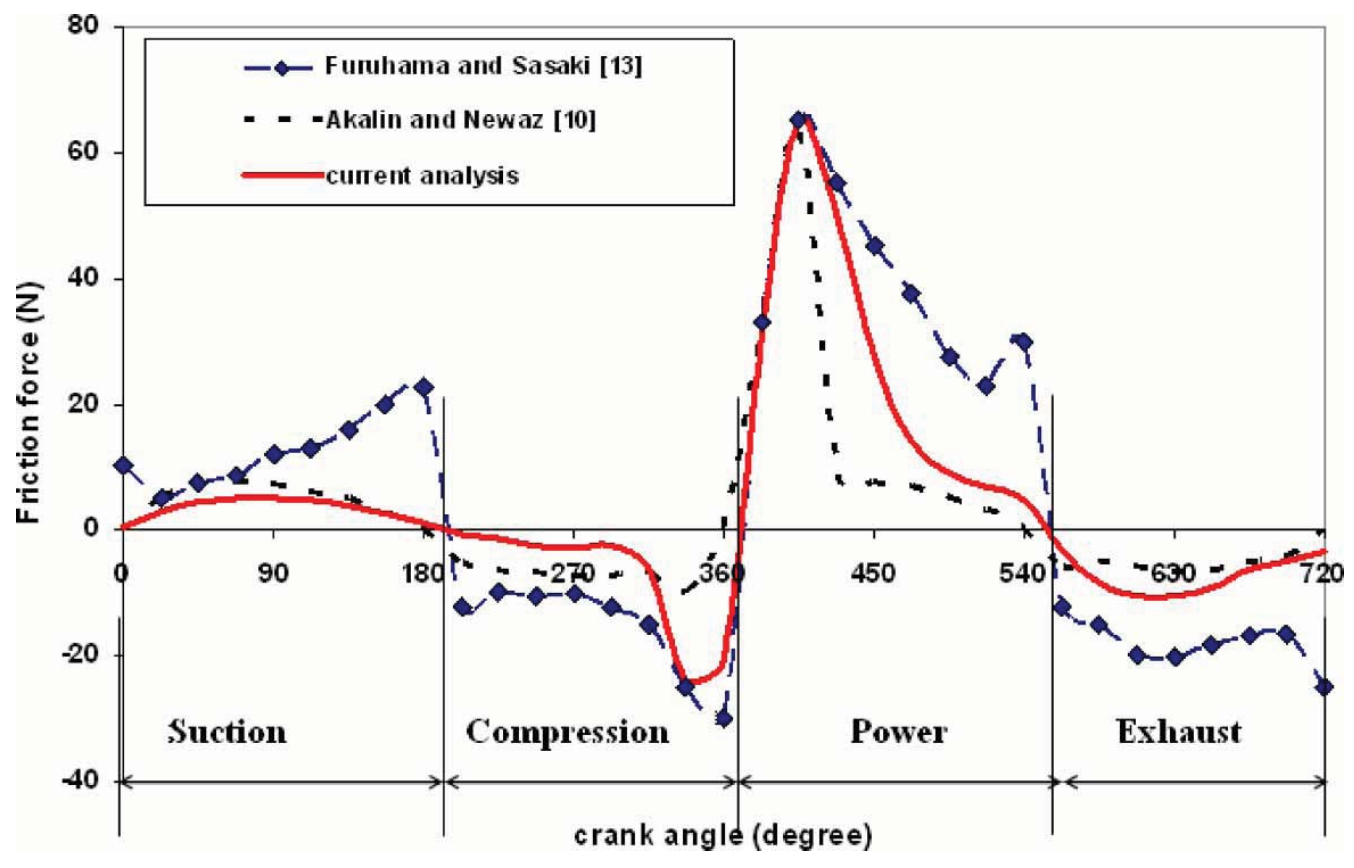

Fig. 13 Comparison of current work with other numerical predictions and measurements

and a pin offset of $1.69 \mathrm{~mm}$. A large fly wheel was used to minimize speed variation, resulting from the reduced engine inertia due to the carried modifications. Akalin and Newaz [10] verified their numerical predictions with friction measurements of Furuhama and Sasaki [13] which were carried out at the engine speed of $1200 \mathrm{r} / \mathrm{min}$ (Fig. 13). The same approach is used here. Note that the main difference between the current analysis and that of Akalin and Newaz [10] is that the current analysis employs two-dimensional elastohydrodynamic analysis with global ring deformation, while that in reference $[\mathbf{1 0}]$ uses a one-dimensional solution with no global ring distortion.

Quite good agreement is noted between both the predictions and the measurements. The experimental findings consistently show larger friction than those predicted. Experimental results indicate a greater share for boundary friction, evident by sudden rises at the ends of each stroke. This is quite likely as neither of the numerical methods takes into account thermal shear thinning of the lubricant nor asperity adhesion or ploughing deformation in wear of asperities. Such differences are more likely prior to and after each reversal (see film thickness variation in Fig. 10).

Referring back to Fig. 13, contribution due to viscous friction is speed dependent, thus would follow the sliding velocity variations shown in Fig. 8. Deviations from the characteristics are because of boundary friction, which is not speed dependent. This is more evident in the measurements than in the predictions.

\section{CONCLUSION}

The analysis shows the transient nature of the regime of lubrication in ring-bore conjunction. It confirms the general acceptance of mixed and boundary regimes of lubrication at piston reversals, which contribute mostly to parasitic engine losses. It is clear that retention of a film of fluid at the dead centres would be desired, which can best be achieved by surface modifications for retention of reservoirs of lubricant such as laser etched features. The paper also shows that with relatively thin films of lubricant and high speeds of entraining motion, viscous friction also accounts for sizeable friction losses in the power stroke. The remedy for this would be improvements to lubricant rheology to encourage its piezo-viscous action, while guarding against undue thixotropic behaviour. The effect of topography of surface modified features and lubricant additives provides the motivation for future research.

\section{REFERENCES}

1 Ma, M. T., Smith, E. H., and Sherrington, I. Analysis of lubrication and friction for a complete piston-ring pack with an improved oil availability model. Part 2: circumferentially variable film. Proc. Instn Mech. Engrs, Part J: J. Engineering Tribology, 1997, 211, 17-27. DOI: 10.1243/1350650971542282.

2 Bolander, N. W., Steenwyk, B. D., Sadeghi, F., and Gerber, G. R. Lubrication regime transitions at the piston ring-cylinder liner interface. Proc. IMechE, Part J: J. Engineering Tribology, 2005, 129, 19-31. DOI: 10.1243/135065005X9664. 
3 Ruddy, B. L., Dowson, D., and Economou, P. N. The prediction of gas pressures within the ring packs of large bore diesel engines. Proc. Instn Mech. Engrs, Part C: J. Mechanical Engineering Science, 1981, 23, 295-304. DOI: 10.1243/JMES_JOUR_1981_023_054_02.

4 Hill, S. H. and Newman, B. A. Piston ring designs for reduced friction. SAE technical paper 841222, 1984, pp. $1-17$.

5 Okamoto, M. and Sakai, I. Contact pressure distribution of piston rings - calculation based on piston ring contour. SAE technical paper 2001-01-0571, 2001, pp. 1-7.

6 Tian, T. Dynamic behaviours of piston rings and their practical impact. Part 2: oil transport, friction and wear of ring/liner interface and the effects of piston and ring dynamics. Proc. Instn Mech. Engrs, Part J: J. Engineering Tribology, 2002, 216, 229-248. DOI: $10.1243 / 135065002760199970$.

7 Dunaevsky, V. V., Alexandrov, S., and Barlat, F. Fundamentals for analysis of three dimensional distortions of the piston rings. ASME Internal Combustion Engine Conference, 2000, pp. 15-18.

8 Mishra, P. C., Balakrishnan, S., and Rahnejat, H. Tribology of compression ring-to-cylinder contact at reversal. Proc. IMechE, Part J: J. Engineering Tribology, 2008, 222(J7), 815-826. DOI: 10.1243/13506501JET410.

9 Balakrishnan, $\mathbf{S}$. and Rahnejat, $\mathbf{H}$. Isothermal transient analysis of piston skirt-to-cylinder wall contacts under combined axial-lateral-tilting motion. J. Phys. D, Appl. Phys., 2005, 38, 787-799.

10 Akalin, O. and Newaz, G. M. piston ring cylinder bore friction modelling in mixed lubrication regime. Part I: analytical results. Trans. ASME, J. Tribol., 2001, 123, 211-218.

11 Etsion, I. State of the art in laser surface. Trans. ASME, J. Tribol., 2005, 127, 248-253.

12 Patir, N. and Cheng, H. S. Application of average flow model to lubrication between rough sliding surfaces. Tran. ASME, J. Tribol., 1979, 101, 221-230.

13 Furuhama, S. and Sasaki, S. New device for the measurement of piston frictional forces in small engines. SAE technical paper 831284, 1983.

14 Loenne, K. and Ziemba, R. The Goetze cylinder distortion measurement and the possibilities of reducing cylinder distortions. SAE technical paper 880142, 1988, pp. 25-33.

15 Roelands C. J. A. Correlation aspects of the viscositytemperature-pressure relationships of lubricating oils. Druk VRB Kleine der A3-4 Groningen, 1966.

16 Dowson, D. and Higginson, G. R. A numerical solution to the elastohydrodynamic problem. Proc. Instn Mech. Engrs, Part C: J. Mechanical Engineering Science, 1959, 1, 6-15. DOI: 10.1243/JMES_JOUR_1959_001_004_2.

17 Greenwood, J. A. and Tripp, J. H. The contact of two nominally flat surfaces. Proc. Instn Mech. Engrs, Part C: J. Mechanical Engineering Science, 1970, 185, 625-633. DOI: 10.1243/PIME_PROC_1970_185_069_02.

18 Hu, Y., Cheng, H. S., Arai, T., Kobayashi, Y., and Ayoma, S. Numerical simulation of piston ring in mixed lubrication: a non-axi-symmetrical analysis. Trans. ASME, J. Tribol., 1994, 116, 470-478.

19 Rahnejat, H., Balakrishnan, S., King, P. D., and HowellSmith, S. In-cylinder friction reduction using a surface finish optimization technique. Proc. IMechE, Part D:
J. Automobile Engineering, 2006, 220, 1309-1318. DOI: 10.1243/09544070JAUT0282.

20 Gohar, R. and Rahnejat, H. Fundamentals of tribology, 2008 (Imperial College Press, London).

\section{APPENDIX 1}

\section{Notation}

$b$

$E_{\mathrm{b}}$

$E_{\mathrm{r}}$

$E^{\prime}$

$f_{\text {asp }}$

$f_{\mathrm{v}}$

$F$

$F_{\mathrm{e}}$

$F_{\mathrm{g}}$

$h_{0}, h_{i j}$

$I$

$M\left(\theta_{i}, \alpha_{j}\right)$

$n$

$p_{\text {asp }}$

$p_{\mathrm{h}}$

$P_{\mathrm{e}_{i j}}$

$P_{\mathrm{g}}$

$P_{\mathrm{gb}}$

$P_{\text {gf }}$

$P_{1}$

$P_{\mathrm{t}}$

$Q_{j}$

$R_{0}$

$R_{\mathrm{b}}$

$s_{i, j}$

$t$

$U$

V

W

$x, y$

$x_{\mathrm{c}}$

$x_{\text {in }}$ ring axial face-width (m)

modulus of elasticity for liner/bore's

material $\left(\mathrm{N} / \mathrm{m}^{2}\right)$

modulus of elasticity for ring's material $\left(\mathrm{N} / \mathrm{m}^{2}\right)$

effective modulus of elasticity of the

contact $\left(\mathrm{N} / \mathrm{m}^{2}\right)$

asperity friction $(\mathrm{N})$

viscous friction $(\mathrm{N})$

applied load $(\mathrm{N})$

elastic force due to ring tension $(\mathrm{N})$

combustion gas force (N)

rigid gap (clearance), elastic film shape

(m)

second area moment of inertia of the ring $\left(\mathrm{m}^{4}\right)$

applied moment due to ring

displacement $(\mathrm{N} \mathrm{m})$

polynomial fit (bore order)

asperity contact pressure $\left(\mathrm{N} / \mathrm{m}^{2}\right)$

hydrodynamic pressure generated in the film $\left(\mathrm{N} / \mathrm{m}^{2}\right)$

radial elastic pressure of the displaced ring $\left(\mathrm{N} / \mathrm{m}^{2}\right)$

combustion pressure $\left(\mathrm{N} / \mathrm{m}^{2}\right)$

pressure acting at the back of the ring $\left(\mathrm{N} / \mathrm{m}^{2}\right)$

combustion pressure acting on ring

front face $\left(\mathrm{N} / \mathrm{m}^{2}\right)$

pressure at leading edge of the ring $\left(\mathrm{N} / \mathrm{m}^{2}\right)$

pressure at the trailing edge of the ring $\left(\mathrm{N} / \mathrm{m}^{2}\right)$

applied elastic force on the ring circumference $(\mathrm{N})$

undeformed ring radius (m)

nominal bore radius $(\mathrm{m})$

undeformed axial ring profile ( $\mathrm{mm}$ )

time (s)

speed of entraining motion $(\mathrm{m} / \mathrm{s})$

speed of side-leakage $(\mathrm{m} / \mathrm{s})$

contact load $(\mathrm{N})$

coordinate directions

cavitation boundary (film rupture

location) (m)

inlet meniscus position in the ring axial direction (m) 
$\dot{x}$

$\alpha_{j}$

$\delta_{i, j}$

$\Delta_{i, j}$

$\Delta R_{\mathrm{a}}$

$\Delta t$

$\eta$

$\eta_{0}$

$\theta$

$\kappa$

$\lambda$

$\mu$

$v_{\mathrm{r}}$

$v_{\mathrm{b}}$

$\xi_{n}$

$\rho$

$\rho_{0}$

$\sigma_{\text {rms }}$ sliding velocity of the ring $(\mathrm{m} / \mathrm{s})$

circumferential position of applied

elastic force (rad)

localized elastic deformation of the ring

(m)

global in-plane ring deformation (m)

bore-ring radius difference (m)

increment of time (simulation step) (s)

lubricant dynamic viscosity (Pa s)

dynamic viscosity at atmospheric pressure (Pa s)

circumferential location (rad)

undeformed ring depth (m)

Stribeck's oil film parameter

coefficient of friction

Poisson's ratio for the ring material

Poisson's ratio for the liner/bore

material

$n$th order conformability factor

lubricant density $\left(\mathrm{kg} / \mathrm{m}^{3}\right)$

bulk lubricant density at ambient

pressure $\left(\mathrm{kg} / \mathrm{m}^{3}\right)$

root mean square of surface roughness of counterfaces (m)

$\begin{array}{ll}\tau & \text { shear stress }\left(\mathrm{N} / \mathrm{m}^{2}\right) \\ \vartheta & \begin{array}{l}\text { load convergence damping } \\ \text { factor } \\ \text { pressure convergence under-relaxation } \\ \text { factor }\end{array} \\ \Omega & \text { ring-bore/liner gap }(\mathrm{m})\end{array}$

APPENDIX 2

$$
\begin{aligned}
\mathbf{D}^{*}= & (x+\bar{b}) \ln \frac{(y+\bar{a})+\left[(y+\bar{a})^{2}+(x+\bar{b})^{2}\right]^{1 / 2}}{(y-\bar{a})+\left[(y-\bar{a})^{2}+(x+\bar{b})^{2}\right]^{1 / 2}} \\
& +(y+\bar{a}) \ln \frac{(x+\bar{b})+\left[(y+\bar{a})^{2}+(x+\bar{b})^{2}\right]^{1 / 2}}{(x-\bar{b})+\left[(y+\bar{a})^{2}+(x-\bar{b})^{2}\right]^{1 / 2}} \\
& +(x-\bar{b}) \ln \frac{(y-\bar{a})+\left[(y-\bar{a})^{2}+(x-\bar{b})^{2}\right]^{1 / 2}}{(y+\bar{a})+\left[(y+\bar{a})^{2}+(x-\bar{b})^{2}\right]^{1 / 2}} \\
& +(y-\bar{a}) \ln \frac{(x-\bar{b})+\left[(y-\bar{a})^{2}+(x-\bar{b})^{2}\right]^{1 / 2}}{(x+\bar{b})+\left[(y-\bar{a})^{2}+(x+\bar{b})^{2}\right]^{1 / 2}}
\end{aligned}
$$

$\bar{a}$ and $\bar{b}$ are the large and small side of the rectangular contact area. 